\title{
Epithelial cell adhesion molecule is expressed in a subset of sarcomas and correlates to the degree of cytological atypia in leiomyosarcomas
}

\author{
KRISTI WARD $^{1}$, CLARISSA AMAYA $^{1}$, KUNDAN VERMA $^{1}$, DAT TRAN ${ }^{1}$ \\ DOLORES DIAZ ${ }^{1}$, ALIREZA TORABI ${ }^{2}$ and BRAD A. BRYAN ${ }^{1}$ \\ Departments of ${ }^{1}$ Biomedical Sciences and ${ }^{2}$ Pathology, Paul L. Foster School of Medicine, \\ Texas Tech University Health Sciences Center, El Paso, TX 79905, USA
}

Received August 20, 2014; Accepted August 22, 2014

DOI: $10.3892 / \mathrm{mco} .2014 .428$

\begin{abstract}
Epithelial cell adhesion molecule (EpCAM) is a protein involved in cell-to-cell attachment and is considered to be strictly expressed in epithelial tissues and epithelial-derived tumors. Furthermore, EpCAM has been shown to be a negative prognostic marker for several carcinomas. In this study, we performed a genomic meta-analysis of gene expression profiles housed in the Cancer Cell Line Encyclopedia to demonstrate that EpCAM mRNA is expressed at low to moderate levels in certain sarcoma cell lines. We utilized immunohistochemical staining to confirm that the EpCAM protein is expressed in a subset of angiosarcomas and leiomyosarcomas and in all the investigated osteosarcomas. Finally, we conducted a statistical analysis of clinical data to demonstrate that EpCAM protein expression is significantly and directly correlated with the degree of cytological atypia in leiomyosarcomas. In conclusion, this data suggests that, contrary to conventional beliefs, EpCAM is expressed in a subset of sarcomas and is a negative prognostic marker for leiomyosarcomas.
\end{abstract}

\section{Introduction}

Epithelial cell adhesion molecule (EpCAM) is a $40-\mathrm{kDa}$ glycosylated transmembrane cell surface protein that plays an important role in $\mathrm{Ca}^{2+}$ independent hemophilic cell-to-cell adhesion, cell signaling, migration, proliferation and differentiation (1). EpCAM was reported to be exclusively present in epithelial tissues and is highly expressed across a large number of epithelial cancers (2-11). Particular interest has been focused

Correspondence to: Dr Brad A. Bryan, Department of Biomedical Sciences, Paul L. Foster School of Medicine, Texas Tech University Health Sciences Center, 5001 El Paso Drive, MSB1 Room 2111, El Paso, TX 79905, USA

E-mail: brad.bryan@ttuhsc.edu

Key words: sarcoma, epithelial cell adhesion molecule, leiomyosarcoma, angiosarcoma, osteosarcoma, cytological atypia on EpCAM expression as a poor prognostic biomarker across a large number of carcinomas (2,4-6,8-10,12-15).

EpCAM is expressed on carcinosarcomas, which are rare biphenotypic tumors that display characteristics of epithelial as well as sarcomatous elements $(16,17)$. The expression of EpCAM is considered to be absent on purely non-epithelial tumors, such as sarcomas and hematopoietic cancers. However, a recent comprehensive analysis of EpCAM expression across human tumors clearly demonstrated that EpCAM is expressed at weak to intense levels in several soft tissue sarcomas, including angiosarcoma (25\%), epitheloid sarcoma (50\%), fibrosarcoma (22\%) and synovial sarcoma (100\%) (18). An abstract presented at the European Society for Medical Oncology indicated that EpCAM-positive circulating cells were detectable in just under half of all the soft tissue sarcoma patients investigated, although the authors were unable to determine whether the EpCAM-positive cells were of epithelial origin due to direct tumor invasion of blood vessels from the surrounding tissue or tumor cells at the moment of mesenchymal-to-epithelial transition (19). Moreover, induced multidrug resistance in osteosarcomas has been shown to increase the expression of cell adhesion markers, including EpCAM (20).

Despite the substantial evidence described above, whether EpCAM is actually expressed on sarcomas remains debatable. Furthermore, it has not yet been determined whether the previously reported expression of EpCAM on sarcomas is of prognostic significance, as has been reported for multiple carcinomas. In this study, we aimed to determine whether EpCAM is indeed expressed at detectable levels in a subset of sarcomas and provide evidence supporting that the steady-state protein expression level of EpCAM is statistically correlated with the degree of cytological atypia in leiomyosarcomas.

\section{Materials and methods}

Meta-analysis of EpCAM expression. The normalized intensity values of EpCAM mRNA were evaluated using the Cancer Cell Line Encyclopedia (CCLE, www.broadinstitute. org/ccle/home). This dataset compares the mRNA expression, chromosomal copy number variation and massively parallel sequencing data from 947 diverse human cancer lines (21). 
Case material. Tissue arrays of formalin-fixed and paraffin-embedded human angiosarcomas (cat no. SO8010), osteosarcomas (cat no. OS804a) and leiomyosarcomas (cat no. SO804) were obtained from US BioMax, Inc. (Rockville, MD, USA) These clinically characterized tumor samples consisted of $2-\mathrm{mm}$ cores with a section thickness of 4 microns and totaled 6 angiosarcoma, 40 osteosarcoma and 80 leiomyosarcoma cases. The cases were reviewed by a pathologist and the diagnoses were confirmed by histomorphology per established morphological criteria.

Immunohistochemistry. The sections were deparaffinized, rehydrated and treated for antigen retrieval using Trilogy solution (Cell Marque, Rocklin, CA, USA; cat no. 920P-10). To block non-specific binding, the sections were incubated in background block solution (Cell Marque; cat no. 927B-05) at room temperature for $10 \mathrm{~min}$ prior to application of the anti-EpCAM primary antibody diluted 1:100 as per the manufacturer's suggestions (Abcam, Cambridge, UK; cat no. ab71916). The sections were then washed in phosphate-buffered saline with Tween-20 (Cell Marque; cat no. 934B-09) three times for $5 \mathrm{~min}$ per wash and incubated with the CytoScan HRP Detection System (Cell Marque; cat no. 951D-20). Immunostaining was performed using the DAB Substrate kit (Cell Marque; cat no. 957D-20) and counterstained with hematoxylin.

Quantitation of immunohistochemistry. EpCAM immunopositivity was scored semiquantitatively for the percentage of tumor cells stained and staining intensity $(0$, negative; + , weak; ++, moderate; and +++, strong). For statistical analysis, scoring was converted to numerical values $(0,0 ;+, 1$; $++, 2$; and,+++ 3$)$ and the mean values \pm standard error of the mean for leiomyosarcomas exhibiting mild, moderate and severe cytological atypia were calculated. Two tailed t-tests were performed to determine statistical significance, which was set at $\mathrm{P} \leq 0.05$.

\section{Results}

Expression of EPCAM across a diverse array of cancer cell lines. CCLE is a publicly accessible cancer genomic database jointly developed by Novartis and the Broad Institute to systematically interpret mRNA expression, chromosomal copy number variation and massively parallel sequencing data from 947 human cancer lines (21). While these groups primarily utilized this database for predictive modeling of anticancer drug sensitivity, a plethora of genomic data awaits meta-analysis to generate and test potential hypotheses that are formulated by bioinformaticians. Utilizing the data housed in the CCLE, we investigated the steady-state mRNA expression of EpCAM across the diverse array of cancer cell lines (Fig. 1). As expected, EpCAM transcripts were highly expressed in a large number of carcinomas and least expressed in hematopoietic cancers, such as lymphomas. Surprisingly, sarcomas exhibited variable degrees of expression; osteosarcomas displayed moderate levels, while Ewing's sarcoma, chondrosarcoma and mixed soft tissue sarcomas exhibited low levels of EpCAM mRNA expression.

EpCAM $m R N A$ and protein expression in sarcomas. Given the unexpected levels of EpCAM mRNA expression in

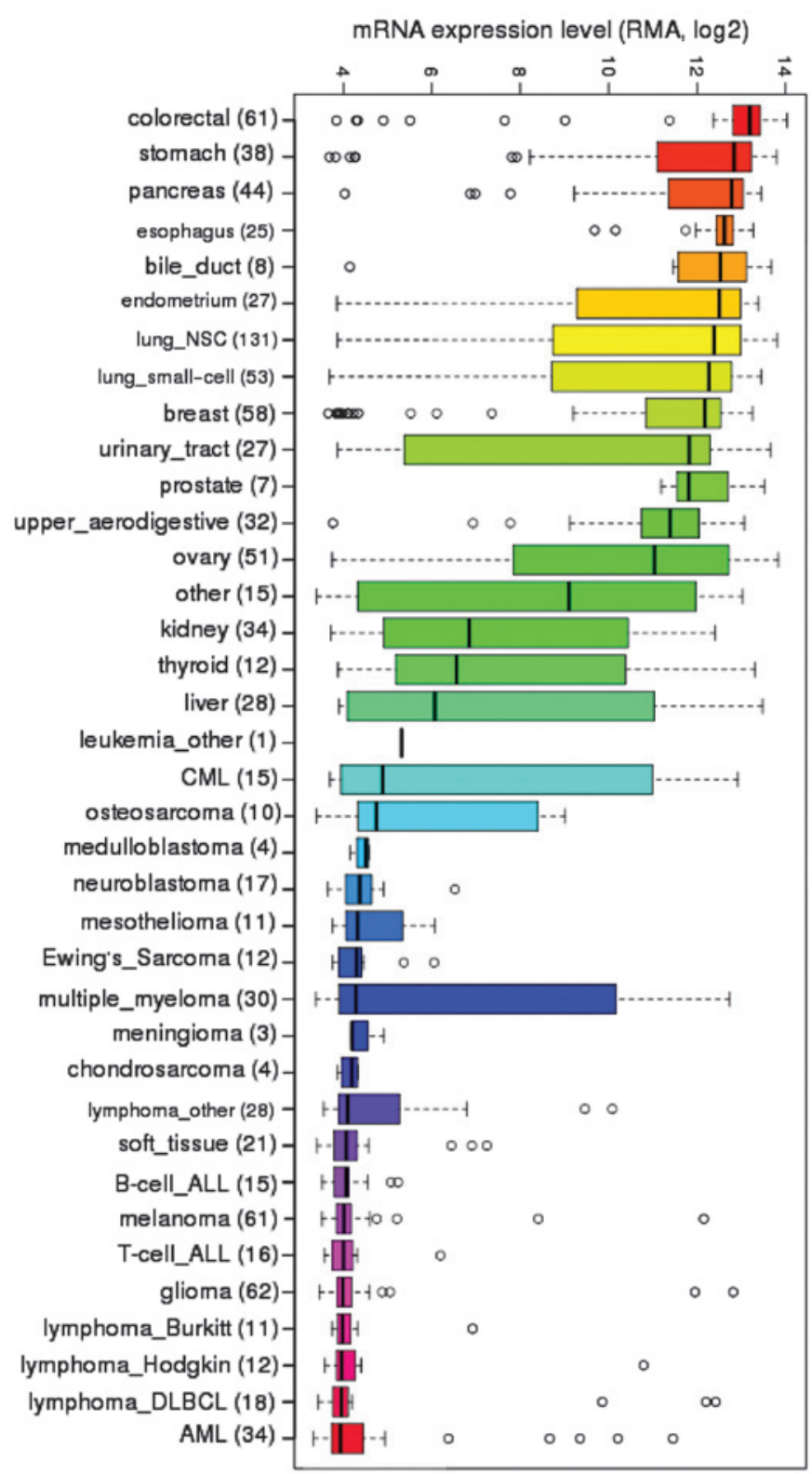

Figure 1. Meta-analysis of epithelial cell adhesion molecule (EpCAM) mRNA expression. Query of EPCAM mRNA expression from the Cancer Cell Line Encyclopedia (CCLE) Portal revealed variable expression of this transcript across a diverse set of tumor cell lines. The numbers in parenthesis along the $y$-axis indicate the number of tumor cell lines used for each sample set. RMA, robust multi-array average; NSC, non-small-cell; CML, chronic myelogenous leukemia; ALL, acute lymphoblastic leukemia; DLBCL, diffuse large B-cell lymphoma; AML, acute myelogenous leukemia.

osteosarcomas based on our genomic meta-analysis, we sought to verify these findings at the protein level in three sarcoma types that our laboratory is currently investigating, namely osteosarcomas, leiomyosarcomas and angiosarcomas. We utilized immunohistochemistry to detect EpCAM protein levels in clinically evaluated human tumor sections from 6 angiosarcomas, 40 osteosarcomas and 80 leiomyosarcomas. EpCAM protein was detected at low levels in half of the angiosarcomas (Table I, Fig. 2) and it was detectable in all the investigated osteosarcomas, with $10 \%$ of the tumors exhibiting weak expression, $87.5 \%$ exhibiting moderate expression and only 1 tumor sample exhibiting strong EpCAM expression (Table II, Fig. 2). We observed mild to moderate 

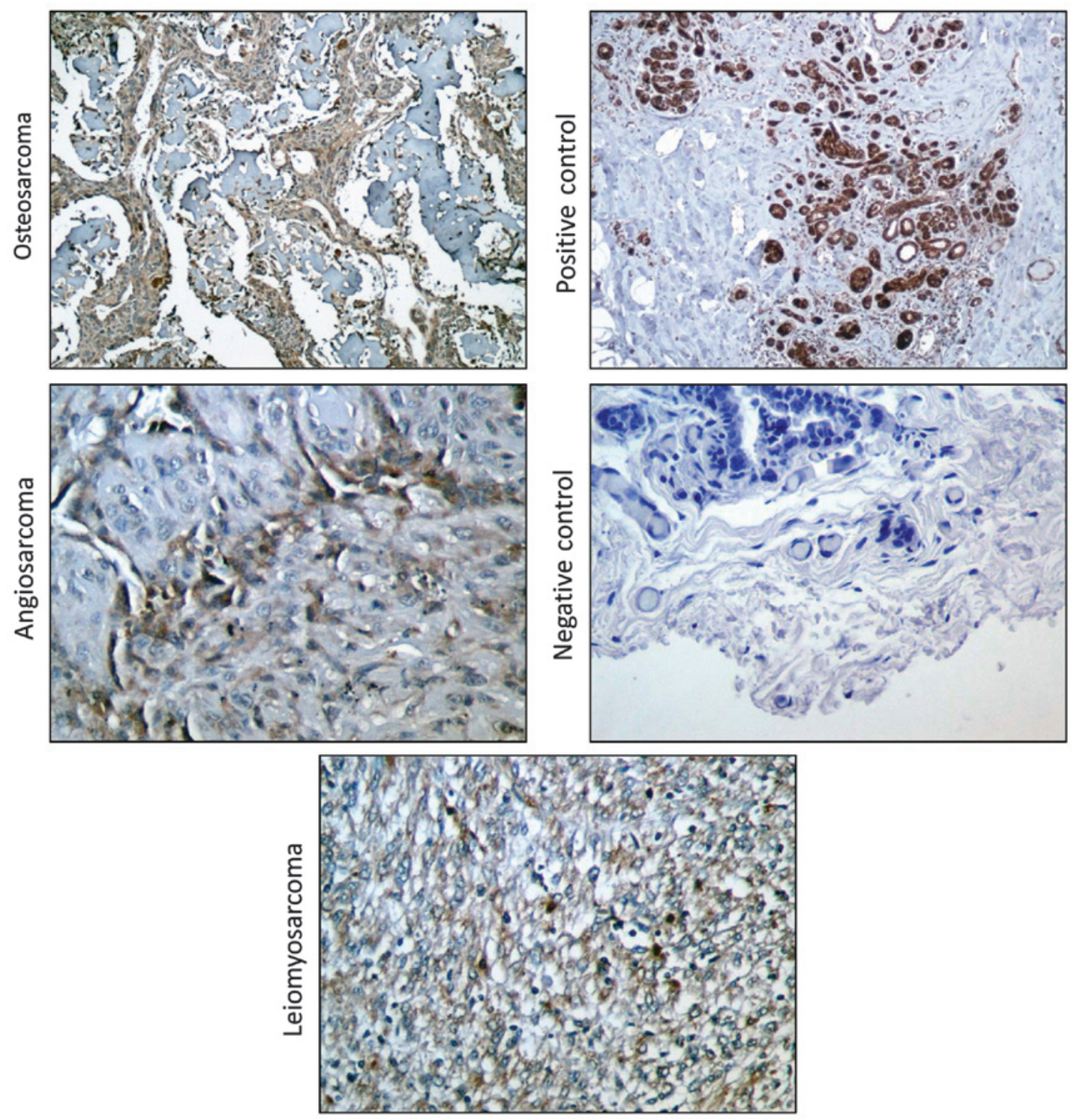

Figure 2. Positive expression of epithelial cell adhesion molecule (EpCAM) in sarcomas. Representative images of immunohistochemical detection of EpCAM steady state protein levels in angiosarcoma, osteosarcoma and leiomyosarcoma tissues. Human epithelial carcinoma sections were stained as a positive control or as a negative control lacking the primary antibody.

Table I. EpCAM protein expression in angiosarcomas.

\begin{tabular}{lclc}
\hline Gender & Age (years) & \multicolumn{1}{c}{ Organ } & Score \\
\hline M & 16 & Fibrous tissue & 0 \\
F & 65 & Fallopian tube & 0 \\
M & 42 & Spleen & 0 \\
M & 47 & Heart & + \\
M & 80 & Liver & + \\
F & 65 & Blood vessel & + \\
\hline
\end{tabular}

EpCAM, epithelial cell adhesion molecule; M, male; F, female.

staining for EpCAM on $62.5 \%$ of the leiomyosarcoma sections that were examined in our analysis, with $51 \%$ of the tumors exhibiting weak and $11 \%$ moderate EpCAM staining (Table III, Fig. 2). Collectively, these data indicate that, contrary to the established scientific belief that EpCAM expression is solely limited to tissues and tumors of epithelial origin, this 'epithelial-specific' protein is indeed expressed in a subset of sarcomas of mesenchymal origin.

Correlation of EpCAM expression with cytological atypia. In addition to the pathological classification, we obtained clinical data on the osteosarcomas and leiomyosarcomas that were utilized in our analysis of EpCAM protein expression. These data included patient gender and age for both tumor types, tumor staging and TNM classification of the osteosarcoma samples and the degree of cytological atypia for the leiomyosarcomas. Given the established prognostic significance of EpCAM expression in human carcinomas, we sought to elucidate whether this extended into sarcomas that expressed this protein. We observed that leiomyosarcomas with moderate and severe cytological atypia exhibited a significantly higher percentage of EpCAM-positive staining 
Table II. EpCAM protein expression in osteosarcomas.

\begin{tabular}{|c|c|c|c|c|c|c|c|c|c|}
\hline Gender & $\begin{array}{c}\text { Age } \\
\text { (years) }\end{array}$ & Stage & TNM & Score & Gender & $\begin{array}{l}\text { Age } \\
\text { years) }\end{array}$ & Organ & Cytological atypia & Score \\
\hline $\mathrm{F}$ & 38 & IA & T1N0M0 & ++ & $\mathrm{F}$ & 50 & Gallbladder & Mild & 0 \\
\hline M & 43 & IA & T1N0M0 & ++ & M & 42 & Abdominal cavity & Mild & 0 \\
\hline $\mathrm{F}$ & 17 & IB & T2N0M0 & +++ & $\mathrm{F}$ & 75 & Esophagus & Mild & 0 \\
\hline M & 41 & IB & T2N0M0 & ++ & M & 50 & Mesentery & Mild & 0 \\
\hline M & 19 & IB & T2N0M0 & ++ & M & 65 & Abdominal cavity & Mild & 0 \\
\hline F & 16 & IIA & T2N0M0 & ++ & $\mathrm{F}$ & 63 & Mesentery & Mild & 0 \\
\hline M & 41 & IIA & T1N0M0 & ++ & M & 37 & Mediastinum & Mild & 0 \\
\hline $\mathrm{F}$ & 15 & IIA & T2N0M0 & + & $\mathrm{F}$ & 62 & Pelvic cavity & Mild & 0 \\
\hline $\mathrm{F}$ & 12 & IIA & T1N0M0 & ++ & $\mathrm{F}$ & 56 & Retroperitoneum & Mild & 0 \\
\hline M & 13 & IIA & T1N0M0 & ++ & $\mathrm{F}$ & 48 & Colon & Mild & 0 \\
\hline $\mathrm{F}$ & 44 & IIA & T1N0M0 & ++ & $\mathrm{F}$ & 39 & Retroperitoneum & Mild & 0 \\
\hline M & 37 & IIA & T1N0M0 & ++ & $\mathrm{M}$ & 72 & Gallbladder & Mild & 0 \\
\hline M & 29 & IIA & T1N0M0 & ++ & $\mathrm{M}$ & 74 & Liver & Mild & 0 \\
\hline M & 32 & IIA & T1N0M0 & ++ & $\mathrm{F}$ & 35 & Retroperitoneum & Mild & 0 \\
\hline M & 47 & IIB & T2N0M0 & + & $\mathrm{F}$ & 45 & Retroperitoneum & Mild & 0 \\
\hline M & 38 & IIB & T2N0M0 & ++ & $\mathrm{F}$ & 51 & Abdominal cavity & Mild & + \\
\hline M & 32 & IIB & T2N0M0 & + & $\mathrm{F}$ & 38 & Fibrous tissue & Mild & + \\
\hline M & 42 & IIB & T2N0M0 & ++ & M & 46 & Colon & Mild & + \\
\hline M & 11 & IIB & T2N0M0 & ++ & $\mathrm{M}$ & 61 & Esophagus & Mild & + \\
\hline M & 38 & IIB & T2NOM0 & ++ & $\mathrm{F}$ & 38 & Retroperitoneum & Mild & + \\
\hline $\mathrm{F}$ & 32 & IIB & T2NOM0 & + & $\mathrm{F}$ & 76 & Mesentery & Mild & + \\
\hline M & 51 & IIB & T2N0M0 & ++ & $\mathrm{F}$ & 43 & Colon & Mild & ++ \\
\hline $\mathrm{F}$ & 14 & IIB & T2NOM0 & ++ & $\mathrm{F}$ & 41 & Retroperitoneum & Mild & ++ \\
\hline $\mathrm{F}$ & 47 & IIB & T2N0M0 & ++ & $\mathrm{F}$ & 46 & Retroperitoneum & Mild & ++ \\
\hline $\mathrm{F}$ & 14 & IIB & T2N0M0 & ++ & $\mathrm{F}$ & 24 & Pelvic cavity & Moderate & 0 \\
\hline $\mathrm{F}$ & 32 & IIB & T2N0M0 & ++ & $\mathrm{M}$ & 36 & Liver & Moderate & 0 \\
\hline $\mathrm{F}$ & 14 & IIB & T2N0M0 & & $\mathrm{F}$ & 38 & Pelvic cavity & Moderate & 0 \\
\hline M & 16 & IIB & T2NOM0 & ++ & $\mathrm{F}$ & 48 & Pelvic cavity & Moderate & 0 \\
\hline M & 18 & $\mathrm{UR}$ & T2NOMO & ++ & $\mathrm{M}$ & 64 & Retroperitoneum & Moderate & 0 \\
\hline M & 23 & IID & 121 voivio & ++ & $\mathrm{M}$ & 80 & Epiploon & Moderate & 0 \\
\hline M & & $11 \mathrm{~B}$ & 1 2NOMIO & ++ & $\mathrm{F}$ & 51 & Abdominal cavity & Moderate & 0 \\
\hline M & 60 & IIB & T2N0M0 & ++ & $\mathrm{M}$ & 57 & Fibrous tissue & Moderate & 0 \\
\hline M & 31 & IIB & T2N0M0 & ++ & $\mathrm{F}$ & 54 & Retroperitoneum & Moderate & 0 \\
\hline $\begin{array}{l}\text { M } \\
\text { F }\end{array}$ & 30 & 111B & T2N0M0 & ++ & $\mathrm{F}$ & 41 & Retroperitoneum & Moderate & 0 \\
\hline $\begin{array}{l}\mathrm{F} \\
\mathrm{M}\end{array}$ & 32 & IIB & T2N0M0 & ++ & $\mathrm{M}$ & 78 & Esophagus & Moderate & 0 \\
\hline $\begin{array}{l}M \\
M\end{array}$ & 64 & IIB & T2N0M0 & ++ & $\mathrm{M}$ & 52 & Abdominal cavity & Moderate & 0 \\
\hline $\begin{array}{l}\mathrm{M} \\
\mathrm{M}\end{array}$ & 35 & IIB & T2N0M0 & ++ & $\mathrm{M}$ & 65 & Esophagus & Moderate & 0 \\
\hline M & 21 & IIB & T2N0M0 & ++ & $\mathrm{M}$ & 45 & Abdominal cavity & Moderate & + \\
\hline M & 51 & IIB & T2N0M0 & ++ & $\mathrm{F}$ & 39 & Retroperitoneum & Moderate & + \\
\hline M & 44 & IIB & T2N0M0 & ++ & $\mathrm{F}$ & 53 & Retroperitoneum & Moderate & + \\
\hline M & 17 & IIB & T2N0M0 & ++ & M & 61 & Retroperitoneum & Moderate & + \\
\hline \multicolumn{5}{|c|}{ EpCAM, epithelial cell adhesion molecule; $\mathrm{M}$, male; $\mathrm{F}$, female. } & $\mathrm{F}$ & 60 & Abdominal cavity & Moderate & + \\
\hline & & & & & $\mathrm{F}$ & 63 & Retroperitoneum & Moderate & + \\
\hline & & & & & $\mathrm{F}$ & 57 & Retroperitoneum & Moderate & + \\
\hline \multirow{4}{*}{\multicolumn{5}{|c|}{$\begin{array}{l}\text { compared to tumors with mild cytological atypia (Fig. } 3 \text { ). } \\
\text { While } 60 \% \text { of leiomyosarcomas displaying mild cytological } \\
\text { atypia were rated as EpCAM-negative, only } 29 \text { and } 20 \% \text { of } \\
\text { EpCAM-negative leiomyosarcomas displayed moderate and }\end{array}$}} & M & 72 & Retroperitoneum & Moderate & + \\
\hline & & & & & $\mathrm{F}$ & 50 & Retroperitoneum & Moderate & + \\
\hline & & & & & M & 57 & Retroperitoneum & Moderate & + \\
\hline & & & & & $\mathrm{M}$ & 45 & Tongue & Moderate & + \\
\hline
\end{tabular}


Table III. Continued.

\begin{tabular}{|c|c|c|c|c|}
\hline Gender & $\begin{array}{c}\text { Age } \\
\text { (years) }\end{array}$ & Organ & Cytological atypia & Score \\
\hline M & 60 & Abdominal cavity & Moderate & + \\
\hline $\mathrm{F}$ & 78 & Retroperitoneum & Moderate & + \\
\hline $\mathrm{F}$ & 42 & Retroperitoneum & Moderate & + \\
\hline $\mathrm{F}$ & 59 & Abdominal cavity & Moderate & + \\
\hline $\mathrm{F}$ & 41 & Retroperitoneum & Moderate & + \\
\hline $\mathrm{F}$ & 44 & Retroperitoneum & Moderate & + \\
\hline $\mathrm{F}$ & 60 & Tongue & Moderate & + \\
\hline M & 49 & Nose & Moderate & + \\
\hline $\mathrm{F}$ & 43 & Retroperitoneum & Moderate & + \\
\hline $\mathrm{F}$ & 40 & Retroperitoneum & Moderate & + \\
\hline M & 42 & Abdominal cavity & Moderate & + \\
\hline $\mathrm{F}$ & 45 & Retroperitoneum & Moderate & + \\
\hline M & 67 & Lung & Moderate & + \\
\hline M & 84 & Skin & Moderate & + \\
\hline $\mathrm{F}$ & 42 & Retroperitoneum & Moderate & + \\
\hline $\mathrm{F}$ & 66 & Skin & Moderate & + \\
\hline M & 38 & Fibrous tissue & Moderate & + \\
\hline $\mathrm{F}$ & 61 & Retroperitoneum & Moderate & ++ \\
\hline $\mathrm{F}$ & 46 & Retroperitoneum & Moderate & ++ \\
\hline $\mathrm{F}$ & 35 & Retroperitoneum & Moderate & ++ \\
\hline $\mathrm{F}$ & 82 & Adrenal gland & Moderate & ++ \\
\hline M & 69 & Abdominal cavity & Moderate & ++ \\
\hline $\mathrm{F}$ & 57 & Breast & Severe & 0 \\
\hline M & 56 & Epiploon & Severe & 0 \\
\hline $\mathrm{F}$ & 73 & Retroperitoneum & Severe & + \\
\hline $\mathrm{F}$ & 52 & Retroperitoneum & Severe & + \\
\hline $\mathrm{F}$ & 52 & Retroperitoneum & Severe & + \\
\hline $\mathrm{F}$ & 58 & Abdominal cavity & Severe & + \\
\hline $\mathrm{F}$ & 46 & Epiploon & Severe & + \\
\hline $\mathrm{F}$ & 35 & Breast & Severe & + \\
\hline $\mathrm{F}$ & 52 & Abdominal cavity & Severe & ++ \\
\hline
\end{tabular}

EpCAM, epithelial cell adhesion molecule; M, male; F, female.

severe cytological atypia, respectively. We utilized statistical analysis as described in the Materials and methods section to correlate EpCAM expression to each known clinical characteristic and demonstrated that EpCAM expression was significantly correlated with the degree of cytological atypia in leiomyosarcomas (EpCAM expression was calculated as follows: mild, $0.50 \pm 0.14$; moderate, $0.83 \pm 0.09$; and severe, $0.89 \pm 0.20 ; \mathrm{P} \leq 0.05$ for all comparisons). These data indicate that the increase in EpCAM expression is directly correlated with the increase in the degree of cytological atypia.

\section{Discussion}

EpCAM has historically been shown to be expressed across epithelial tissues, with a few exceptions (22). Additionally,

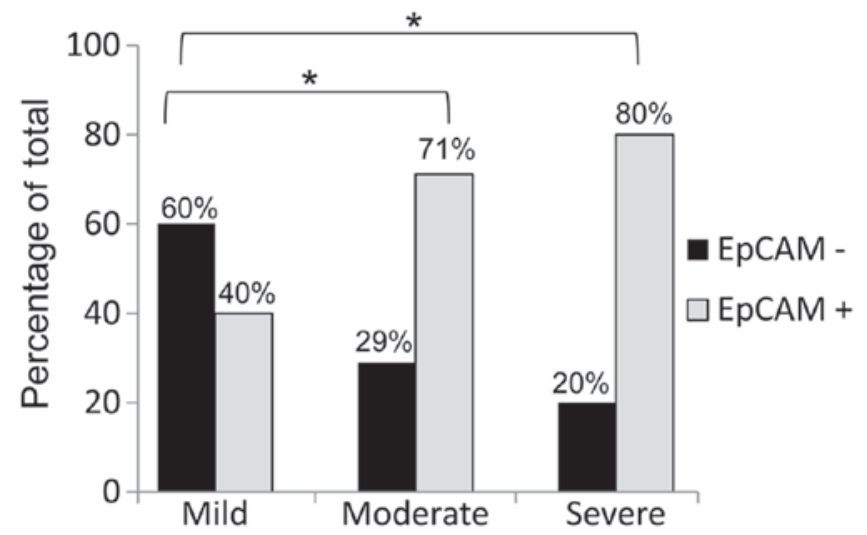

Figure 3. Correlation of epithelial cell adhesion molecule (EpCAM) expression with cytological atypia in leiomyosarcoma. The percentages of EpCAM-positive and -negative leiomyosarcomas are expressed based on the clinical diagnosis of mild, moderate and severe cytological atypia. The actual percentages are represented by the bars in the graph. The asterisk denotes statistical significance $(\mathrm{P} \leq 0.05)$.

EpCAM is highly overexpressed across a wide range of carcinomas and was originally described as the dominant antigen in patients with colon carcinoma $(23,24)$. The expression of this protein has been associated with poor clinical prognosis in patients with a number of carcinomas by functioning as an oncogene and suppressing $\mathrm{CD}^{+}{ }^{+} \mathrm{T}$-cell-dependent immune responses $(2,5,25,26)$. Moreover, use of the EpCAM-specific monoclonal antibody edrecolomab and the tri-functional antibody catumaxomab in patients with metastatic cancers has demonstrated positive antitumor effects (27-30), suggesting that targeting EpCAM may prove to be efficacious against certain carcinomas.

By mining the gene expression data of various cancer cell lines deposited in the CCLE portal, we quickly noticed that, despite the common scientific belief that EpCAM is strictly expressed in tissues of epithelial origin, tumors of mesenchymal origin, such as osteosarcomas, displayed moderate expression of this gene. This prompted us to delve further into EpCAM expression to demonstrate that, of the mesenchymal tumors investigated in our analysis, all osteosarcomas and over half of the leiomyosarcomas and angiosarcomas expressed EpCAM protein at detectable levels, as determined by immunohistochemistry. Our data confirmed the previous findings by Went et al (18), suggesting that $22-100 \%$ of sarcomas express weak to intense levels of the EpCAM protein. Given that EpCAM has been extensively reported to be a prognostic biomarker for carcinomas, we sought to determine whether the prognostic significance of this protein extends to sarcomas. Using established clinical data from our panel of osteosarcoma and leiomyosarcoma samples, we identified a direct statistical correlation between EpCAM expression and the degree of cytological atypia in leiomyosarcomas. Cytological atypia is one of the most significant prognostic factors for leiomyosarcoma (31); thus, similar to the results obtained for carcinomas, EpCAM expression is a negative prognostic factor for leiomyosarcomas.

This study, contrary to the current clinical perception that EpCAM is solely expressed in epithelial tissues, suggests that EpCAM mRNA and protein expression may be used as 
a prognostic biomarker for leiomyosarcoma severity and will potentially expand the number of cancers exhibiting susceptibility to immunotherapy against EpCAM.

\section{References}

1. Litvinov SV, Bakker HA, Gourevitch MM, Velders MP and Warnaar SO: Evidence for a role of the epithelial glycoprotein 40 (Ep-CAM) in epithelial cell-cell adhesion. Cell Adhes Commun 2: 417-428, 1994.

2. Gastl G, Spizzo G, Obrist P, Dünser M and Mikuz G: Ep-CAM overexpression in breast cancer as a predictor of survival. Lancet 356: 1981-1982, 2000

3. Heinzelmann-Schwarz VA, Gardiner-Garden M, Henshall SM, et al: Overexpression of the cell adhesion molecules DDR1, Claudin 3, and Ep-CAM in metaplastic ovarian epithelium and ovarian cancer. Clin Cancer Res 10: 4427-4436, 2004.

4. Songun I, Litvinov SV, van de Velde CJ, Pals ST, Hermans J and van Krieken JH: Loss of Ep-CAM (CO17-1A) expression predicts survival in patients with gastric cancer. Br J Cancer 92: 1767-1772, 2005

5. Spizzo G, Went P, Dirnhofer S, et al: Overexpression of epithelial cell adhesion molecule (Ep-CAM) is an independent prognostic marker for reduced survival of patients with epithelial ovarian cancer. Gynecol Oncol 103: 483-488, 2006.

6. Kimura H, Kato H, Faried A, et al: Prognostic significance of EpCAM expression in human esophageal cancer. Int J Oncol 30 171-179, 2007.

7. Shim HS, Yoon BS and Cho NH: Prognostic significance of paired epithelial cell adhesion molecule and E-cadherin in ovarian serous carcinoma. Hum Pathol 40: 693-698, 2009.

8. Schmidt M, Hasenclever D, Schaeffer M, et al: Prognostic effect of epithelial cell adhesion molecule overexpression in untreated node-negative breast cancer. Clin Cancer Res 14: 5849-5855, 2008.

9. Schmidt M, Petry IB, Böhm D, et al: Ep-CAM RNA expression predicts metastasis-free survival in three cohorts of untreated node-negative breast cancer. Breast Cancer Res Treat 125: 637-646, 2011.

10. Akita H, Nagano H, Takeda Y, et al: Ep-CAM is a significant prognostic factor in pancreatic cancer patients by suppressing cell activity. Oncogene 30: 3468-3476, 2011.

11. Pietzner K, Woopen H, Richter R, et al: Expression of epithelial cell adhesion molecule in paired tumor samples of patients with primary and recurrent serous ovarian cancer. Int J Gynecol Cancer 23: 797-802, 2013.

12. Battista MJ, Cotarelo C, Jakobi S, et al: Overexpression of epithelial cell adhesion molecule protein is associated with favorable prognosis in an unselected cohort of ovarian cancer patients. J Cancer Res Clin Oncol 140: 1097-1102, 2014.

13. Seligson DB, Pantuck AJ, Liu X, et al: Epithelial cell adhesion molecule (KSA) expression: pathobiology and its role as an independent predictor of survival in renal cell carcinoma. Clin Cancer Res 10: 2659-2669, 2004.

14. Varga M, Obrist P, Schneeberger S, et al: Overexpression of epithelial cell adhesion molecule antigen in gallbladder carcinoma is an independent marker for poor survival. Clin Cancer Res 10: 3131-3136, 2004.
15. Stoecklein NH, Siegmund A, Scheunemann P, et al: Ep-CAM expression in squamous cell carcinoma of the esophagus: a potential therapeutic target and prognostic marker. BMC Cancer 6: 165, 2006.

16. Choijamts B, Jimi S, Kondo T, et al: $\mathrm{CD} 133^{+}$cancer stem cell-like cells derived from uterine carcinosarcoma (malignant mixed Müllerian tumor). Stem Cells 29: 1485-1495, 2011.

17. Paniz Mondolfi AE, Jour G, Johnson M, et al: Primary cutaneous carcinosarcoma: insights into its clonal origin and mutational pattern expression analysis through next-generation sequencing. Hum Pathol 44: 2853-2860, 2013.

18. Went PT, Lugli A, Meier S, et al: Frequent EpCam protein expression in human carcinomas. Hum Pathol 35: 122-128, 2004

19. Vincenzi B, Rossie E, Zoccoli A, et al: Circulating tumor cells in soft tissue sarcomas. Poster presented at 37th EMSO Congress, 2012. http://www.oxfordjournals.org/our_journals/annonc/ downloads/annonc23s9-v2 pdf. Accessed June, 2014.

20. Sanchez-Carbayo M, Belbin TJ, Scotlandi K, et al: Expression profiling of osteosarcoma cells transfected with MDR1 and NEO genes: regulation of cell adhesion, apoptosis, and tumor suppression-related genes. Lab Invest 83: 507-517, 2003.

21. Barretina J, Caponigro G, Stransky N, et al: The Cancer Cell Line Encyclopedia enables predictive modelling of anticancer drug sensitivity. Nature 483: 603-607, 2012.

22. Schmelzer E and Reid LM: EpCAM expression in normal, non-pathological tissues. Front Biosci 13: 3096-3100, 2008.

23. Herlyn M, Steplewski Z, Herlyn D and Koprowski H: Colorectal carcinoma-specific antigen: detection by means of monoclonal antibodies. Proc Natl Acad Sci USA 76: 1438-1442, 1979.

24. Patriarca C, Macchi RM, Marschner AK and Mellstedt H: Epithelial cell adhesion molecule expression (CD326) in cancer: a short review. Cancer Treat Rev 38: 68-75, 2012.

25. Gutzmer R, Li W, Sutterwala S, et al: A tumor-associated glycoprotein that blocks MHC class II-dependent antigen presentation by dendritic cells. J Immunol 173: 1023-1032, 2004.

26. Münz M, Kieu C, Mack B, Schmitt B, Zeidler R and Gires O: The carcinoma-associated antigen EpCAM upregulates c-Myc and induces cell proliferation. Oncogene 23: 5748-5758, 2004.

27. Fagerberg J, Hjelm AL, Ragnhammar P, Frödin JE, Wigzell H and Mellstedt H: Tumor regression in monoclonal antibody-treated patients correlates with the presence of anti-idiotype-reactive T lymphocytes. Cancer Res 55: 1824-1827, 1995.

28. Chelius D, Ruf P, Gruber P, et al: Structural and functional characterization of the trifunctional antibody catumaxomab. MAbs 2: 309-319, 2010.

29. Seimetz D, Lindhofer H and Bokemeyer C: Development and approval of the trifunctional antibody catumaxomab (anti-EpCAM x anti-CD3) as a targeted cancer immunotherapy. Cancer Treat Rev 36: 458-467, 2010.

30. Ströhlein MA and Heiss MM: The trifunctional antibody catumaxomab in treatment of malignant ascites and peritoneal carcinomatosis. Future Oncol 6: 1387-1394, 2010.

31. Bell SW, Kempson RL and Hendrickson MR: Problematic uterine smooth muscle neoplasms. A clinicopathologic study of 213 cases. Am J Surg Pathol 18: 535-558, 1994. 